\title{
Large-Eddy Simulations of Trade Wind Cumuli: Investigation of Aerosol Indirect Effects
}

\author{
Huiwen Xue and Graham Feingold \\ NOAA/Earth System Research Laboratory, Boulder, Colorado
}

(Manuscript received 23 August 2005, in final form 21 October 2005)

\begin{abstract}
The effects of aerosol on warm trade cumulus clouds are investigated using a large-eddy simulation with size-resolved cloud microphysics. It is shown that, as expected, increases in aerosols cause a reduction in precipitation and an increase in the cloud-averaged liquid water path (LWP). However, for the case under study, cloud fraction, cloud size, cloud-top height, and depth decrease in response to increasing aerosol concentration, contrary to accepted hypotheses associated with the second aerosol indirect effect. It is found that the complex responses of clouds to aerosols are determined by competing effects of precipitation and droplet evaporation associated with entrainment. As aerosol concentration increases, precipitation suppression tends to maintain the clouds and lead to higher cloud LWP, whereas cloud droplets become smaller and evaporate more readily, which tends to dissipate the clouds and leads to lower cloud fraction, cloud size, and depth. An additional set of experiments with higher surface latent heat flux, and hence higher LWP and drizzle rate, was also performed. Changes in cloud properties due to aerosols have the same trends as in the base runs, although the magnitudes of the changes are larger. Evidence for significant stabilization (or destabilization) of the subcloud layer due to drizzle is not found, mainly because drizzling clouds cover only a small fraction of the domain. It is suggested that cloud fraction may only increase with increasing aerosol loading for larger clouds that are less susceptible to entrainment and evaporation. Finally, it is noted that at any given aerosol concentration the dynamical variability in bulk cloud parameters such as LWP tends to be larger than the aerosol-induced changes in these parameters, indicating that the second aerosol indirect effect may be hard to measure in this cloud type. The variability in cloud optical depth is, however, dominated by changes in aerosol, rather than dynamics.
\end{abstract}

\section{Introduction}

It has been hypothesized that increases in atmospheric aerosol concentrations may lead to a cooling effect on climate through modification of cloud microphysical processes. Increases in aerosol concentrations will increase the number concentration of cloud condensation nuclei (CCN) and cloud droplets, reduce the droplet size, and hence increase the cloud reflectance (all else being equal; Twomey 1974, 1977, 1991). For low-level clouds, radiating at approximately the same temperature as the earth's surface, this will cool the planetary system, particularly if these clouds overlay a dark ocean surface. However, clouds are dynamical systems and consideration of feedbacks in the system, associated with precipitation, entrainment, radiation, and

Corresponding author address: Dr. Huiwen Xue, NOAA/Earth System Research Laboratory, 325 Broadway, Boulder, CO 80305. E-mail: huiwen.xue@noaa.gov surface fluxes, must also be taken into account. Albrecht (1989) suggested that cloud liquid water content (LWC), fractional cloudiness, and cloud lifetime in stratocumulus will increase through aerosol-induced precipitation suppression, resulting in an additional increase in cloud albedo and cooling (the second aerosol indirect effect). Precipitation suppression due to aerosol and the subsequent increase in the rate of entrainment in stratocumulus may also change cloud depth and hence cloud reflectance.

Observational evidence of aerosol effects on clouds abounds. For example, Warner and Twomey (1967) observed decreases in cloud droplet sizes associated with abundant aerosol emanating from sugarcane fires. Warner (1968) hypothesized that this same biomass burning aerosol was likely suppressing precipitation. Precipitation suppression by aerosol has been confirmed by observations in various types of clouds, such as ship tracks (Ferek et al. 2000), and shallow cumulus clouds (Heymsfield and McFarquhar 2001; Hudson and 
Yum 2001). Aerosol effects on clouds were well documented during the North Atlantic Regional Experiment (Leaitch et al. 1996), the Monterey Area Ship Track Experiments (Durkee et al. 2000), the Aerosol Characterization Experiment-II CLOUDY COLUMN experiments (Brenguier et al. 2000), and numerous others. Satellite- and surface-based remote sensing has also been widely used to identify aerosol effects on clouds (e.g., Kaufman and Nakajima 1993; Feingold et al. 2003), but questions remain regarding the ability of these methods to quantify the indirect effects (Feingold 2003).

Observations of the second aerosol indirect effect are particularly difficult and therefore their magnitude is much more uncertain than the first indirect effect. This is partly because the microphysical-dynamicalradiative feedbacks involved are complex and can lead to different responses of clouds to aerosol. In addition, changes in aerosol are likely accompanied by changes in meteorological conditions, making it difficult to separate aerosol effects from meteorological effects. Even the responses of cloud liquid water, cloud coverage, and depth to aerosols are not clear. Observations show that LWP can increase, decrease, or remain approximately the same as the aerosol concentration increases (Platnick et al. 2000; Coakley and Walsh 2002; Han et al. 2002).

From the modeling perspective, many of the original hypotheses for aerosol effects on clouds have emanated from rather simple models, and only for particular atmospheric soundings and cloud types. While these have served an important role and focused the community's efforts, care must be taken when projecting results for one cloud type on another. For example, the Albrecht (1989) study addressed the effect of aerosol on precipitation in stratocumulus using a one-dimensional turbulence closure model, but the results are often assumed to be valid for other cloud types.

Studies of aerosol indirect effects using large-eddy simulation (LES) models have been carried out over the past decade for boundary layer clouds, particularly for the stratocumulus regime. Aerosol and meteorological effects can be separated, and the feedbacks elucidated by keeping meteorological conditions the same and changing only the aerosol loadings. It has been shown that different feedbacks exist depending on the amount of precipitation. For heavily drizzling stratocumulus clouds, drizzle removes liquid water and stabilizes the boundary layer to inhibit mixing, as proposed by Albrecht (1989). Reduced drizzle at higher CCN thus leads to higher LWP; that is, a positive second aerosol indirect effect (Stevens et al. 1998). For very lightly drizzling stratocumulus clouds, evaporative cooling of drizzle drops at cloud base can destabilize the subcloud layer and lead to more vigorous development of clouds (Feingold et al. 1996). Under these conditions, reduced drizzle may in some circumstances result in lower LWP and a negative second aerosol indirect effect (Jiang et al. 2002). Ackerman et al. (2004) showed that the humidity of air above stratocumulus clouds and cloud-top entrainment have an important bearing on surface precipitation rate and the response of LWP to changes in aerosol. Only when the overlying air is humid or droplet concentrations are very low does sufficient precipitation reach the surface to allow cloud water to increase with droplet concentration. When the overlying air is dry and leads to light or no precipitation at the surface, LWC decreases with increased CCN. Lu and Seinfeld (2005) also used LES to confirm that statistically, a positive second aerosol indirect effect occurs in heavily drizzling stratocumulus clouds and a negative one occurs in lightly drizzling clouds.

Cumulus clouds are another common type of boundary layer cloud; their coverage is on average $12 \%$ over ocean and 5\% over land (Warren et al. 1986a,b), which is high enough to affect the global radiation budget. Cumulus clouds are also an important part of the hydrological cycle. The dynamics of cumulus clouds has been extensively studied in the past because of its significant roles in moisture and energy transport to the free atmosphere. However, much uncertainty remains regarding aerosol-cloud interactions and implications for climate forcing in such clouds. Cumulus clouds differ from stratocumulus clouds in many ways: morphology, driving force, entrainment, life cycle, and so on. Thus, mechanisms pertaining to the aerosol indirect effects for stratocumulus clouds are not necessarily applicable to cumulus clouds. For example, the fraction of drizzling clouds is often small in cumulus clouds and the drizzling cells are often in the stage of dissipation when drizzle forms. Therefore, the dynamical feedbacks due to drizzle in cumulus clouds may not be as significant as in stratocumuli (Jiang and Cotton 2000). In addition, cloud fraction and lifetime are important properties of cumulus clouds and clouds undergoing the transition from stratocumulus to cumulus.

That aerosol particles do indeed affect clouds is not in question, but there still exists considerable uncertainty as to the extent of this effect. Clearly our understanding of these processes is still incomplete. For example, it is not known how aerosol effects on clouds compare to the inherent variability of a cloud system due to dynamical forcing. The effects of aerosols on cloud properties such as cloud liquid water and precipitation need to be addressed for better representation of the aerosol indirect effects in climate models (e.g., Lohmann and Feichter 2004). LES provides a useful 
framework for investigation for these questions and perhaps a basis for parameterization.

Here we investigate the effects of aerosols on warm trade cumuli using an LES model with size-resolved microphysics. The aerosol-induced changes in precipitation, LWP, cloud fraction, cloud size, and depth in western Atlantic trade cumuli are studied, and the underlying mechanisms for the changes are discussed. Section 2 is a brief description of the model and the case setup. Section 3 presents the results and section 4 the discussion. The conclusions are presented in section 5 .

\section{LES model and case setup}

The dynamical framework used in this study is an anelastic LES model described by Stevens et al. (1999). The momentum equations are solved by a leapfrog scheme while scalar terms are integrated using a forward-in-time method. Advection terms in the momentum equation are solved using fourth-order centered differences. Advection of scalars uses second-order upwind advection with slope limiting using a monotone centered algorithm to maintain monotonicity. The lateral boundary conditions are cyclic. The model has $64 \times 64 \times 75$ grid points, with spacing $\Delta x=\Delta y=100$ $\mathrm{m}$, and $\Delta z=40 \mathrm{~m}$; that is, the domain size is $6.4 \mathrm{~km} \times$ $6.4 \mathrm{~km}$ in the horizontal and $3 \mathrm{~km}$ in the vertical. The time step is $1.5 \mathrm{~s}$. Sensitivity studies were also performed using $\Delta x=\Delta y=50 \mathrm{~m}, \Delta z=40 \mathrm{~m}$, and $\Delta t=0.5 \mathrm{~s}$.

The model has fixed surface sensible heat, latent heat, and momentum fluxes. The subgrid-scale model employs the Smagorinsky scheme to calculate eddy viscosity and diffusivity. Rayleigh friction is applied to the top five model layers for momentum and temperature in order to prevent waves from reflecting from the top of the domain.

The bin-microphysics model coupled to the LES has been described by Feingold et al. (1996) and Stevens et al. (1996). The drop spectrum is divided into 33 fixed size bins with mass doubling from one bin to the next, covering the radius range $1.5-2500 \mu \mathrm{m}$. Equations for drop number and mass are solved within each bin using a two-moment method that is less diffusive than single moment methods for similar numbers of bins (Tzivion et al. 1987). Activation, condensation/evaporation, collision-coalescence and sedimentation are simulated. The aerosol is assumed to be fully soluble ammonium sulfate with a lognormal size distribution $\left(r_{g}=0.1 \mu \mathrm{m}\right.$, $\left.\sigma_{g}=1.5\right)$. The particle concentration is varied as discussed below, but for any given simulation it is constant over time and space. Giant CCN (GCCN) are not considered, although they have been demonstrated to be important for warm rain initiation. For example, Fein- gold et al. (1999) showed that the addition of GCCN to clean conditions has little impact because drizzle is usually active anyway at low CCN concentrations. At high $\mathrm{CCN}$ concentrations, GCCN have the greatest potential for enhancing the collection process, but the drizzle amount is expected to be much less than that in clean conditions. Therefore, the effect of addition of GCCN is not investigated here. Activation of aerosol is based on the calculated supersaturation and equilibrium theory, where aerosols with sizes larger than the dry critical size are activated. The activation scheme also considers the number concentration of droplets already present, such that the drop concentration cannot exceed the total aerosol concentration (Clark 1974). The removal of aerosol from the boundary layer due to precipitation is not simulated, but this is not expected to be significant for these weakly precipitating trade cumuli. The model therefore solves 72 prognostic equations (three velocity components, liquid water potential temperature, total water mixing ratio, supersaturation, 33 scalars for droplet number, and 33 scalars for droplet mass). Pressure is a diagnostic variable in the model.

The case selected for this study is a trade cumulus based on the Barbados Oceanographic and Meteorology Experiment (BOMEX), during which steady-state cumulus convection was observed for a period of several days (Holland and Rasmusson 1973). The initial (idealized) profiles (Fig. 1; an average of 22 and 23 June 1969 soundings) are the same as those prescribed in the fourth intercomparison study of the Global Water and Energy Experiment (GEWEX) Cloud System Studies (GCSS) Working Group 1 (Siebesma et al. 2003). The current study only diverges from the intercomparison case in that radiative effects and large-scale forcings are not considered. Typically, radiation schemes respond to cloud LWP and since the intent here is to focus on aerosol effects on microphysics and dynamics, it was deemed desirable to remove feedbacks via radiation. Because this is not a case study, we do not compare results with the observations. Rather, the case is used as an idealized and well-studied dynamical framework within which to investigate the effects that aerosol may have on trade cumuli.

Two sets of simulations were performed. In each set, aerosol concentration was varied over the range 25, 50, 450 , and $2000 \mathrm{mg}^{-1}$ (the preferred mixing ratio units of $\mathrm{mg}^{-1}$ are roughly equal to $\mathrm{cm}^{-3}$ ) to represent clean to polluted conditions. Surface forcing such as surface buoyancy and moisture fluxes are fixed. In the first set, the fixed surface fluxes are

$$
\begin{aligned}
& \left(\overline{w^{\prime} \theta^{\prime}}\right)_{s}=1.3 \times 10^{-2} \mathrm{~K} \mathrm{~m} \mathrm{~s}^{-1}, \\
& \left(\overline{\bar{w}^{\prime} q_{t}^{\prime}}\right)_{s}=3.9 \times 10^{-5} \mathrm{~m} \mathrm{~s}^{-1},
\end{aligned}
$$



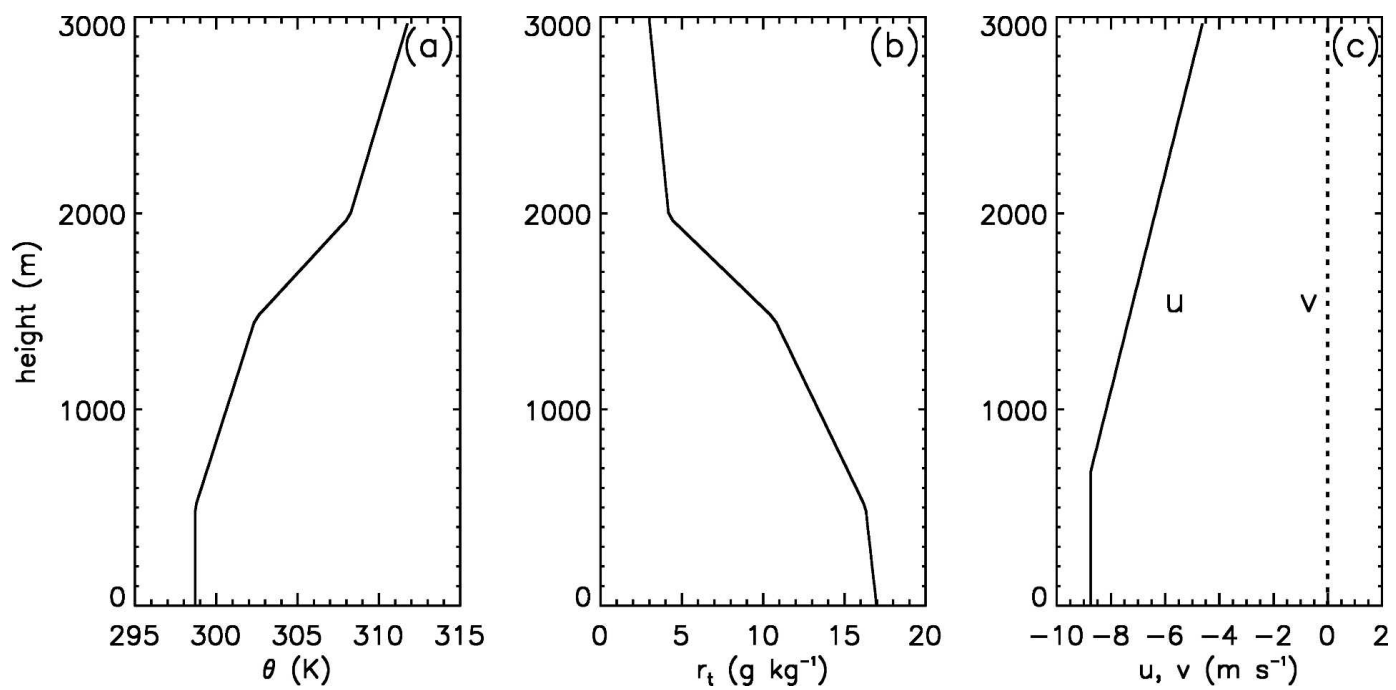

FIG. 1. Initial profiles based on the BOMEX 22 and 23 Jun 1969 soundings: (a) dry potential temperature, (b) total water mixing ratio, and (c) horizontal winds.

which are equivalent to 15 and $115 \mathrm{~W} \mathrm{~m}^{-2}$, respectively. The Bowen ratio is 0.13 . The surface momentum flux is

$$
\left(\overline{\mathbf{v}^{\prime} w^{\prime}}\right)_{s}=-u_{*}^{2} \frac{\mathbf{v}}{|\mathbf{v}|},
$$

where $u_{*}=0.25 \mathrm{~m} \mathrm{~s}^{-1}$. The horizontal velocities $u$ and $v$ are based on values at the lowest grid level above the surface. This set of simulations produces weak drizzle, as will be shown in the next section.

In the second set of experiments, the surface sensible heat flux is kept the same as in the first set, but the latent heat flux is increased to

$$
\left(\overline{w^{\prime} q_{t}^{\prime}}\right)_{s}=8.6 \times 10^{-5} \mathrm{~m} \mathrm{~s}^{-1},
$$

equivalent to $250 \mathrm{~W} \mathrm{~m}^{-2}$, and a Bowen ratio of 0.06 . This enhances LWP and drizzle formation, and allows us to test the effects of drizzle on cloud properties and boundary layer structure. Note that this value of latent heat flux is at the high end of the range measured during BOMEX (Holland 1972). A total of eight simulations were performed for the standard model setup described above. All the simulations were run for $6 \mathrm{~h}$, but the first $2 \mathrm{~h}$ are considered model spinup time and analysis is only performed on the last $4 \mathrm{~h}$. Various other sensitivity studies were also performed as described in sections $4 \mathrm{a}, \mathrm{c}$.

\section{Results}

\section{a. Base runs}

Figure 2 shows the time evolution of cloud fraction, LWP, cloud-top height, cloud-base height, vertically in- tegrated turbulent kinetic energy (TKE) over the model domain, and surface precipitation rate for the clean $\left(N_{a}=25 \mathrm{mg}^{-1}\right)$ and polluted $\left(N_{a}=2000 \mathrm{mg}^{-1}\right)$ cases for the base runs. (The intermediate aerosol mixing ratios are omitted at this stage for clarity.) The cloud fraction is defined as the fraction of the grid columns that have LWP $>10 \mathrm{~g} \mathrm{~m}^{-2}$. Cloud-top height is defined as the highest grid point that has LWC $>0.01$ $\mathrm{g} \mathrm{m}^{-3}$ in each cloudy column. A similar definition applies to cloud-base height. The cloud-top height and cloud-base height shown here are the averages over all cloudy columns at each time instant. Other definitions of cloud boundaries and cloud fraction were tried. For example, cloud boundaries were calculated based on a criterion that $r_{t} / r_{s}$ be greater than 1 , where $r_{t}$ is the total mixing ratio (vapor plus water) and $r_{s}$ is the saturation vapor mixing ratio. Results were very similar and did not change the observed trends. After the first $2 \mathrm{~h}$ of spinup, cloud fraction and LWP approach a steady state, while cloud-top height, cloud-base height, and TKE increase with time. The cloud properties shown here are in quantitative agreement with the GCSS intercomparison study of the BOMEX case. Cloud properties are generally changed when aerosol concentration varies. Precipitation is negligible in the polluted case so the domain-averaged surface precipitation rate is only shown for the clean case.

To better illustrate the changes due to aerosol, cloud properties shown in Fig. 2 are averaged over the last 4 $\mathrm{h}$ of simulations for each aerosol concentration and plotted in Fig. 3. The standard deviations of the various parameters at each aerosol loading are shown as a vertical line. Although cloud-top height, cloud-base height, 

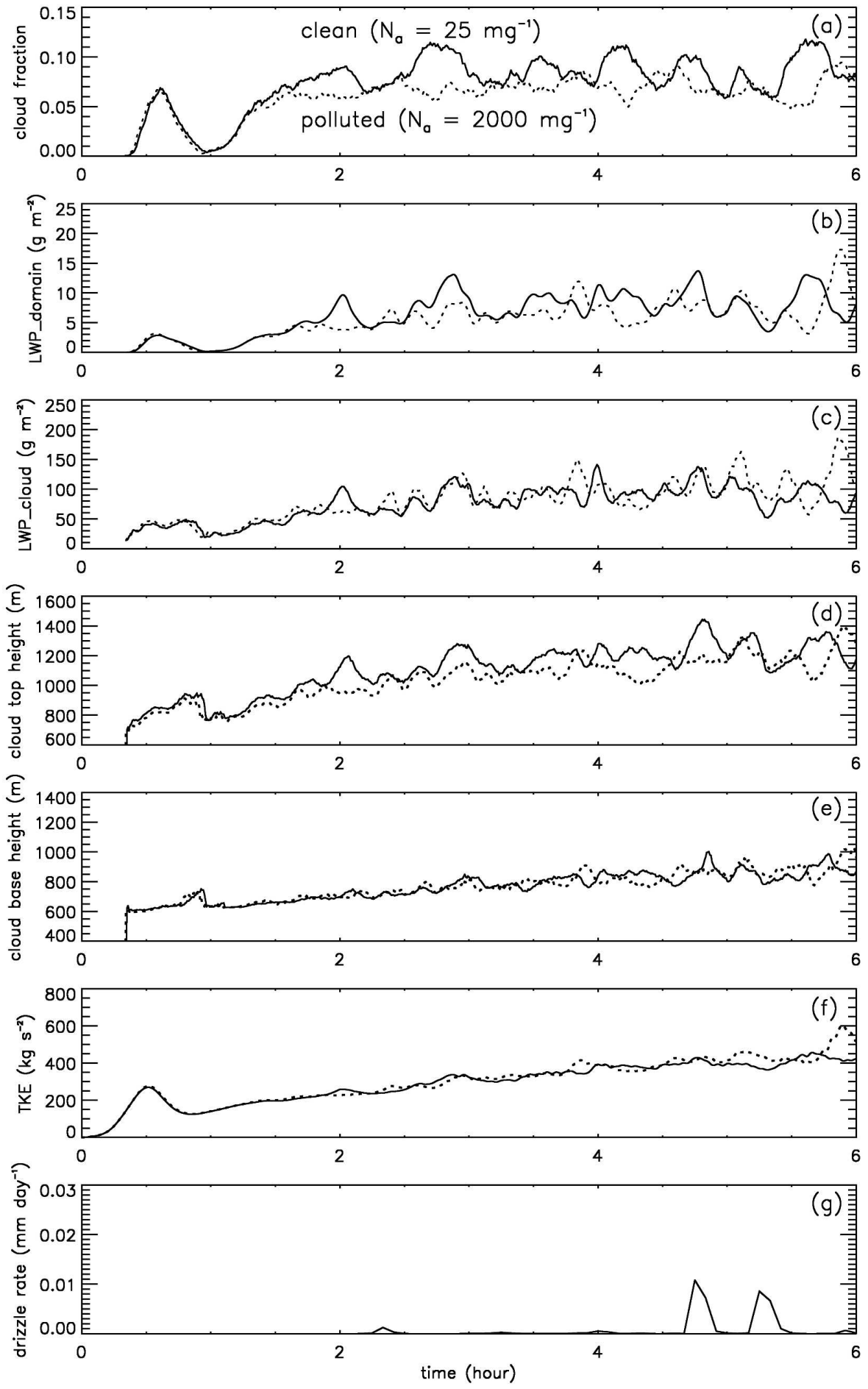

FIg. 2. Time series for the clean $\left(N_{a}=25 \mathrm{mg}^{-1}\right)$ and polluted $\left(N_{a}=2000 \mathrm{mg}^{-1}\right)$ cases for the base simulations: (a) cloud fraction, (b) domain-averaged LWP, (c) cloud-averaged LWP (averaged over cloudy columns), (d) cloud-top height, (e) cloud-base height, (f) vertically integrated TKE, and (g) domain-averaged surface precipitation rate. Surface precipitation rate in the polluted case is negligible so only the precipitation for the clean case is shown. Line types are solid for the clean case and dashed for the highly polluted case, are used consistently in all figures. 

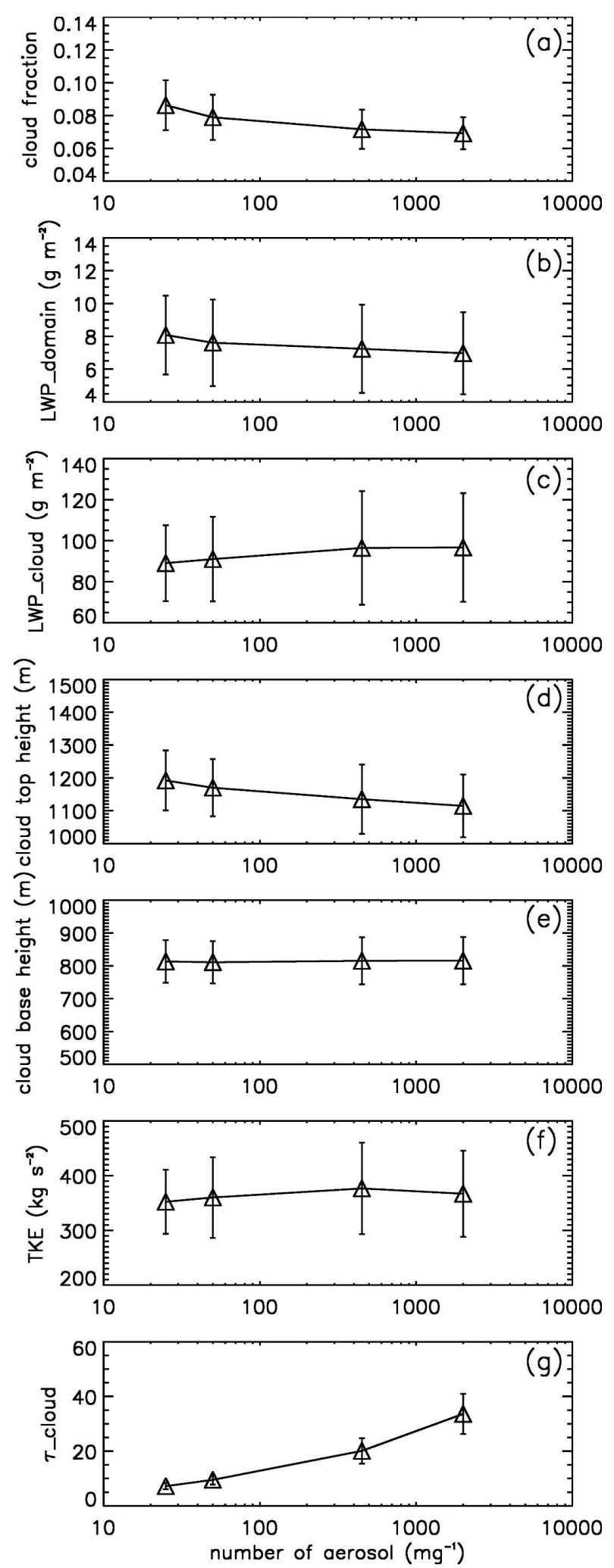

FIG. 3. Cloud properties averaged over the last $4 \mathrm{~h}$ of simulations as a function of aerosol mixing ratios for the base runs: (a) cloud fraction, (b) domain-averaged LWP, (c) cloud-averaged LWP, (d) cloud-top height, (e) cloud-base height, (f) vertically and TKE are not in steady state over the averaging time period, the averages still provide information on how the simulated clouds are affected by aerosol. Changes in various parameters are summarized in Table 1. Cloud fraction decreases from 0.086 to 0.069 as CCN increases from 25 to $2000 \mathrm{mg}^{-1}$, contrary to what might be expected by extrapolating Albrecht's (1989) result. Cloud-top height decreases from 1192 to $1115 \mathrm{~m}$ while cloud base does not vary much, implying that cloud depth is reduced. TKE increases with increasing aerosol mixing ratio. Notable features in Figs. 2 and 3 include the increase in cloud optical depth (calculated in the visible assuming an extinction efficiency of 2), suppression of precipitation, and a modest increase in cloud-averaged LWP $(+8.5 \%$, see Table 1$)$, but a decrease in cloud fraction $(-20 \%)$, cloud-top height, depth $(-21 \%)$, and domain-averaged LWP $(-14 \%)$. This suggests that mechanisms other than precipitation play an important role in determining the cloud properties. Droplet evaporation, and associated dynamical feedbacks, as will be discussed later, have significant effects on these small trade cumulus clouds. Note that the domain-averaged LWP and cloud-averaged LWP respond to the aerosols in opposite ways because cloud fraction decreases with increasing aerosol (see discussion below). Also of note is the fact that the standard deviations of many of the parameters at a given aerosol mixing ratio are typically larger than the variability because of aerosol changes, even for this significant range of $N_{a}$. This is particularly true of the LWP variables, cloud-top height, and TKE. This indicates that for the case under study, although aerosol has distinct influence on cloud features, this influence is smaller than the dynamical variability of the cloud system in the absence of aerosol effects. In the case of cloud optical depth, the dynamical influence is much smaller and the variability is primarily driven by the changes in aerosol.

\section{b. Experiments with higher surface latent heat flux}

Since lightly drizzling and heavily drizzling clouds will have different dynamics and likely respond differently to aerosol, more heavily drizzling trade cumulus clouds are also investigated. For the current case, this is achieved by increasing the surface latent heat flux as described in section 2. Figure 4 shows the time evolution of the cloud fraction, LWP, cloud-top height, vertically integrated TKE, and surface drizzle rate for the

integrated TKE, and ( $\mathrm{g}$ ) cloud optical depth. The vertical lines show \pm 1 standard deviation from the mean. 
TABLE 1. Average cloud properties over the last $4 \mathrm{~h}$ of simulations. Numbers in parentheses represent standard deviations. The percentage differences between the clean and polluted cases (polluted - clean) are also shown.

\begin{tabular}{|c|c|c|c|c|c|c|}
\hline & \multicolumn{3}{|c|}{ Base case } & \multicolumn{3}{|c|}{ Higher surface flux case } \\
\hline & $N_{a}=25 \mathrm{mg}^{-1}$ & $N_{a}=2000 \mathrm{mg}^{-1}$ & Diff $(\%)$ & $N_{a}=25 \mathrm{mg}^{-1}$ & $N_{a}=2000 \mathrm{mg}^{-1}$ & Diff $(\%)$ \\
\hline Cloud fraction & $0.086(0.015)$ & $0.069(0.01)$ & -20 & $0.133(0.014)$ & $0.100(0.01)$ & -25 \\
\hline LWP_domain $\left(\mathrm{g} \mathrm{m}^{-2}\right)$ & $8.1(2.4)$ & $7.0(2.5)$ & -14 & $16.0(3.4)$ & $13.3(3.3)$ & -17 \\
\hline LWP_cloud $\left(\mathrm{g} \mathrm{m}^{-2}\right)$ & $89(19)$ & $97(26)$ & 8.5 & $117(20)$ & $131(31)$ & 12 \\
\hline Cloud top (m) & $1192(92)$ & $1115(96)$ & -6.5 & $1342(92)$ & $1211(103)$ & -9.8 \\
\hline Cloud base (m) & $813(65)$ & $816(72)$ & 0.3 & $861(76)$ & $846(77)$ & -1.6 \\
\hline TKE $\left(\mathrm{kg} \mathrm{s}^{-2}\right)$ & $352(59)$ & $367(79)$ & 4.2 & $547(87)$ & $617(109)$ & 13 \\
\hline Cloud depth (m) & $379(50)$ & $299(39)$ & -21 & $481(53)$ & $365(48)$ & -24 \\
\hline Drop effective radius $(\mu \mathrm{m})$ & $23.4(3.4)$ & $4.42(0.14)$ & -81 & $31.4(7.4)$ & $4.66(0.16)$ & -85 \\
\hline Optical depth & $7.2(1.1)$ & $33.6(7.4)$ & 367 & $8.5(1.1)$ & $42.8(7.9)$ & 404 \\
\hline
\end{tabular}

clean $\left(N_{a}=25 \mathrm{mg}^{-1}\right)$ and polluted $\left(N_{a}=2000 \mathrm{mg}^{-1}\right)$ cases when surface latent heat flux is increased. Compared to the base runs, clouds in this set of simulations generally have higher cloud fraction, LWP, cloud-top height, cloud-base height and depth, TKE, and precipitation rate. The maximum surface precipitation rate for individual clouds in the clean case can reach $40 \mathrm{~mm}$ day $^{-1}$ (locally and instantaneously, based on analysis of output at 5-min intervals). The drizzle rate is significantly suppressed as the aerosol mixing ratio increases and surface drizzle is again negligible for the polluted case.

In Fig. 5, the averages of the time series over the last $4 \mathrm{~h}$ are shown for each aerosol concentration. On average, cloud fraction decreases from 0.133 to 0.100 when aerosol concentration increases from 25 to 2000 $\mathrm{mg}^{-1}$. Cloud top is reduced from 1342 to $1211 \mathrm{~m}$. Changes in cloud properties due to aerosol show the same trends as in the base runs (Table 1): suppressed precipitation, increased cloud-averaged LWP (+12\%), and decreased drop effective radius $(-85 \%)$, but decreased cloud fraction $(-25 \%)$, cloud-top height, depth $(-24 \%)$, and domain-averaged LWP (-17\%).

Compared to the base runs, the stronger removal of liquid water by drizzle in these simulations has a more marked effect on cloud liquid water in the clean case: cloud-averaged LWP increases by $12 \%$ because of the increase in aerosol, compared to the $8.5 \%$ in the base runs, and cloud fraction, depth, and domain-averaged LWP still decrease with increasing aerosol. The qualitative consistency between these and the base case simulations suggest that well-defined processes and feedbacks are responsible for this behavior. These are discussed below.

\section{Discussion}

The results indicate that cloud responses to increases in aerosol do not necessarily follow widely accepted hypotheses. Below we elucidate some of the processes that explain the model behavior. Unless otherwise noted the analysis pertains to the base case simulations. Analysis of the more strongly precipitating cases shows even stronger clean/polluted differences so that the base case results can be considered representative.

\section{a. Droplet evaporation and precipitation effects}

Figures $6 a, b$ show the profiles of water evaporation and condensation rates over the last $4 \mathrm{~h}$ of simulation for the clean and polluted cases. These rates are recorded locally at every grid point, every $5 \mathrm{~min}$, and then averaged horizontally over the domain. Because high concentrations of droplets promote both condensation growth and evaporation, the water condensation and evaporation rates are both larger in the polluted case. The net condensation/evaporation rate in Fig. 6c shows that clouds generally have net evaporation above 1200 $\mathrm{m}$, roughly where the average cloud top is located (Fig. $3 d)$. The polluted case has a higher net evaporation rate, corresponding to a lower cloud-top height and depth compared to the clean case (Fig. 2). The polluted case also has a lower net condensation rate in the layer between 700 and $1200 \mathrm{~m}$, where the clouds reside. Although more water is condensed in the polluted case (Fig. 6b), droplets at the cloud boundaries also evaporate faster because of the higher surface-to-volume ratio of the droplets. The case is made here, and in subsequent discussion, that this is a key process that leads to smaller cloud fraction (Fig. 6d), and smaller domainaveraged LWC (Fig. 6e). Cloud sizes are also smaller, as will be shown in section $4 \mathrm{~d}$. However, the cloudaveraged LWC (Fig. 6f) is larger in the polluted case, especially at lower levels. Note that these profiles should not be interpreted as indicating average cloud depths of $1400 \mathrm{~m}$. Rather, individual clouds have a wide range of depths that fill the height range from 600 to $2000 \mathrm{~m}$, with mean cloud bases and tops shown in 

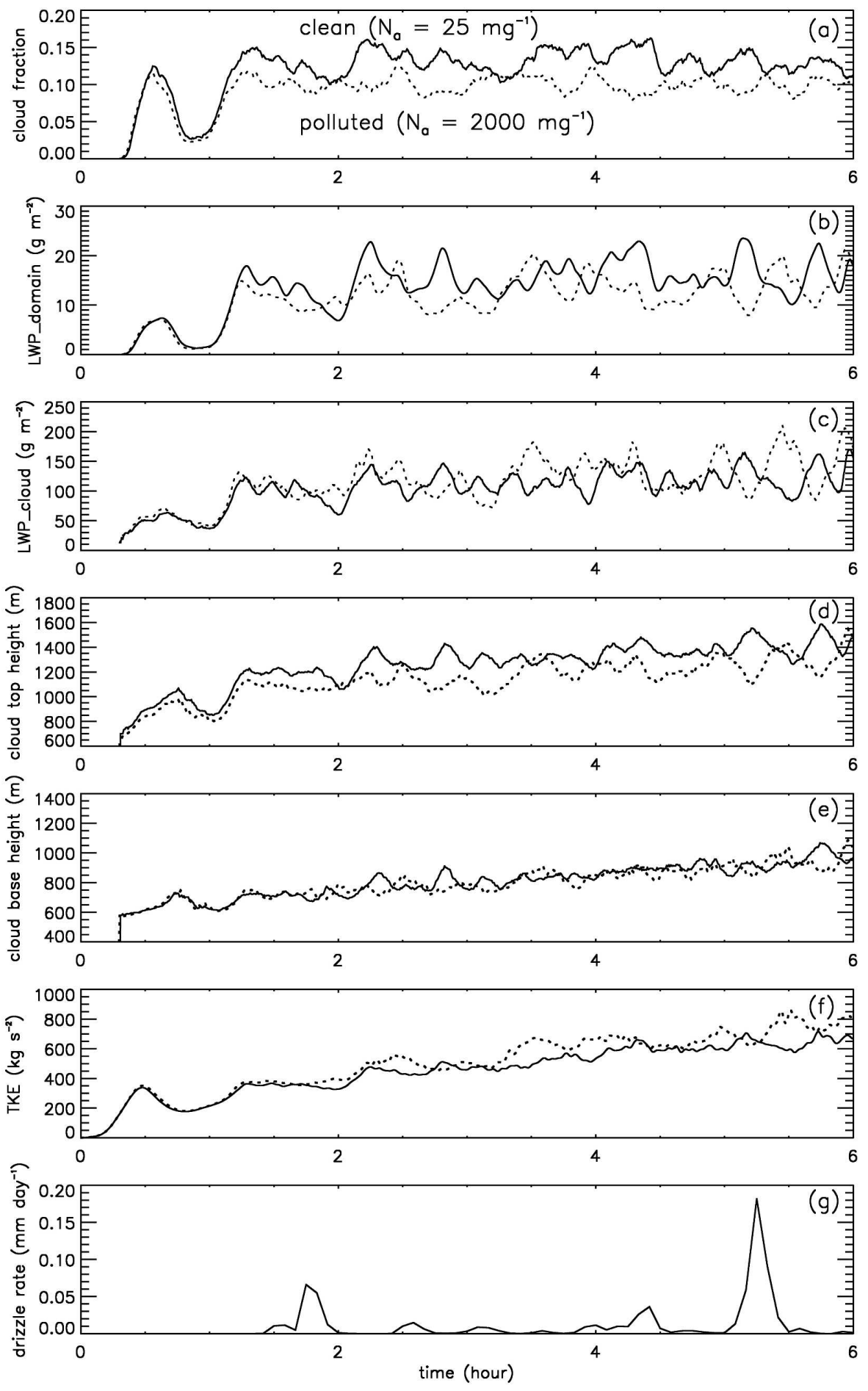

FIG. 4. As in Fig. 2, but for the higher flux simulations.

Figs. 2 and 3. At the height corresponding to the average cloud top, cloud-top processes are averaged together with in-cloud processes to produce the mean profiles. With increasing height (approaching $2000 \mathrm{~m}$ ), a progressively stronger signal of cloud-top effects is ob- tained. Note too that Figs. 6e,f suggest that the polluted clouds have higher cloud tops, in apparent contradiction to Figs. 2 and 3. Close examination of the model output shows the higher cloud tops for polluted clouds evident in Figs. 6e,f derive from a very small number of 

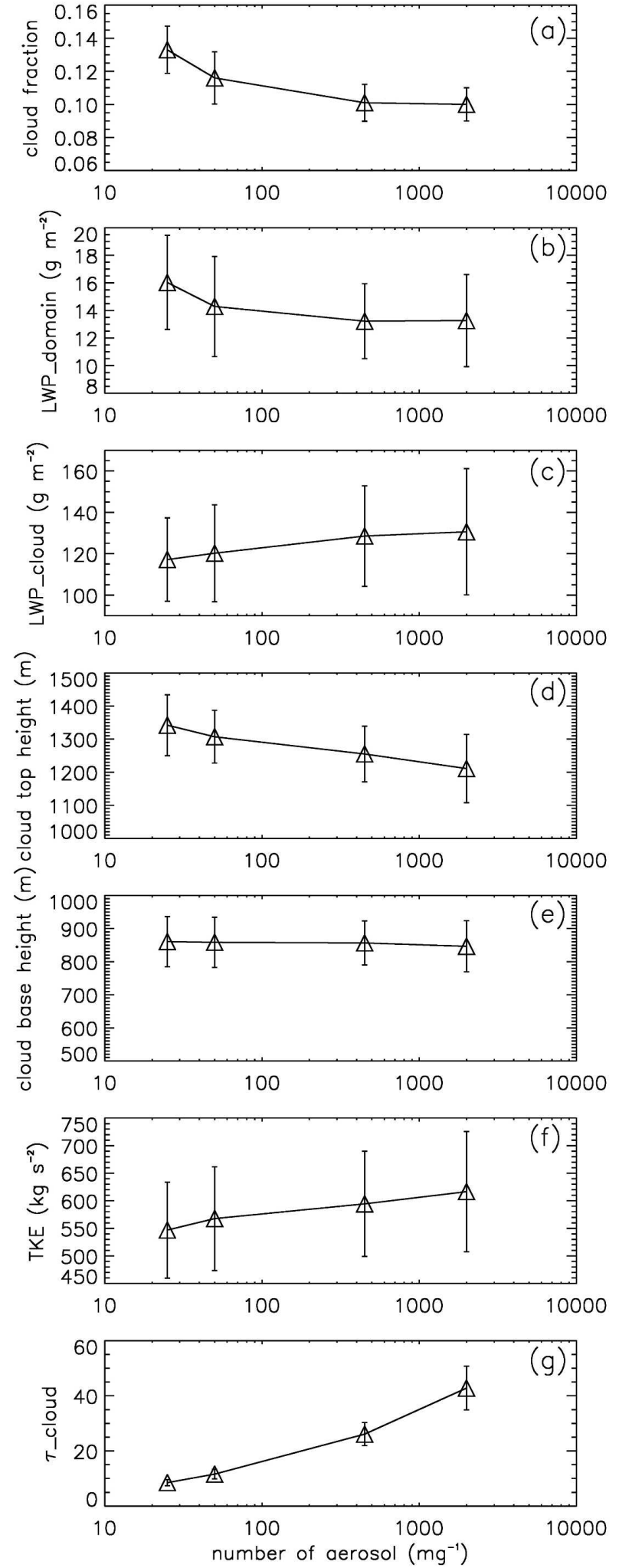

FIG. 5. As in Fig. 3, but for the higher flux simulations. clouds that penetrate to deeper levels. Contributions from these clouds to the statistics shown in Figs. 2 and 3 are small because of the preponderance of shallow clouds in the case studied.

Two interesting questions arise. 1) Why does the cloud-averaged LWP increase with increasing aerosol while the cloud depth decreases with increasing aerosol? 2) Why do the cloud-averaged LWC and LWP increase with increasing aerosol while the domainaveraged LWC and LWP decrease with increasing aerosol. Why do the cloud averages and domain averages seem to tell different stories?

Regarding question 1), we note that cloud water is regulated by phase changes, precipitation, and surface resupply of moisture. For fixed surface moisture fluxes, the response of the cloud liquid water to aerosol depends on whether the net phase change (mediated by dynamics and entrainment) or precipitation dominates. In the polluted clouds, aerosol-induced precipitation suppression tends to increase the LWC, especially at the lower levels of the clouds (Fig. 6f). Near cloud top, the polluted clouds may have smaller or similar LWC compared to the clean clouds due to more efficient droplet evaporation (Fig. 6f). Since the LWP is an integration of LWC over the depth of the cloud, the cloud-averaged LWP in the polluted case is still higher even though the cloud depth is lower. Thus, for the current case, precipitation suppression dominates phase change differences and results in an increase in cloud water with increasing aerosol.

Regarding question 2), we make the case that under polluted conditions, more efficient droplet evaporation at cloud boundaries leads to a smaller cloud fraction. Since the domain-averaged LWP depends on both cloud fraction and cloud-averaged LWP, it is the reduction in cloud fraction that results in the domainaveraged LWP decrease with increasing aerosol. In general, the response of the domain-averaged LWP to aerosol changes will be a function of the individual responses of cloud fraction and cloud-average LWP to aerosol. Table 1 shows that cloud fraction decreases as a result of increasing aerosol $(-20 \%$ for an increase from 25 to $2000 \mathrm{mg}^{-1}$ ), while cloud-averaged LWP increases $(+8.5 \%)$. Therefore, the combined effect is that the domain-averaged LWP decreases $(-14 \%)$. Although the system does not respond in a linear manner, this simple demonstration shows that cloud properties are determined by multiple factors that may respond to aerosol in opposite ways. The net effect depends on which one dominates.

To test the relative contributions of precipitation and condensation/evaporation to aerosol-induced effects, a set of simulations that neglected collision-coalescence 

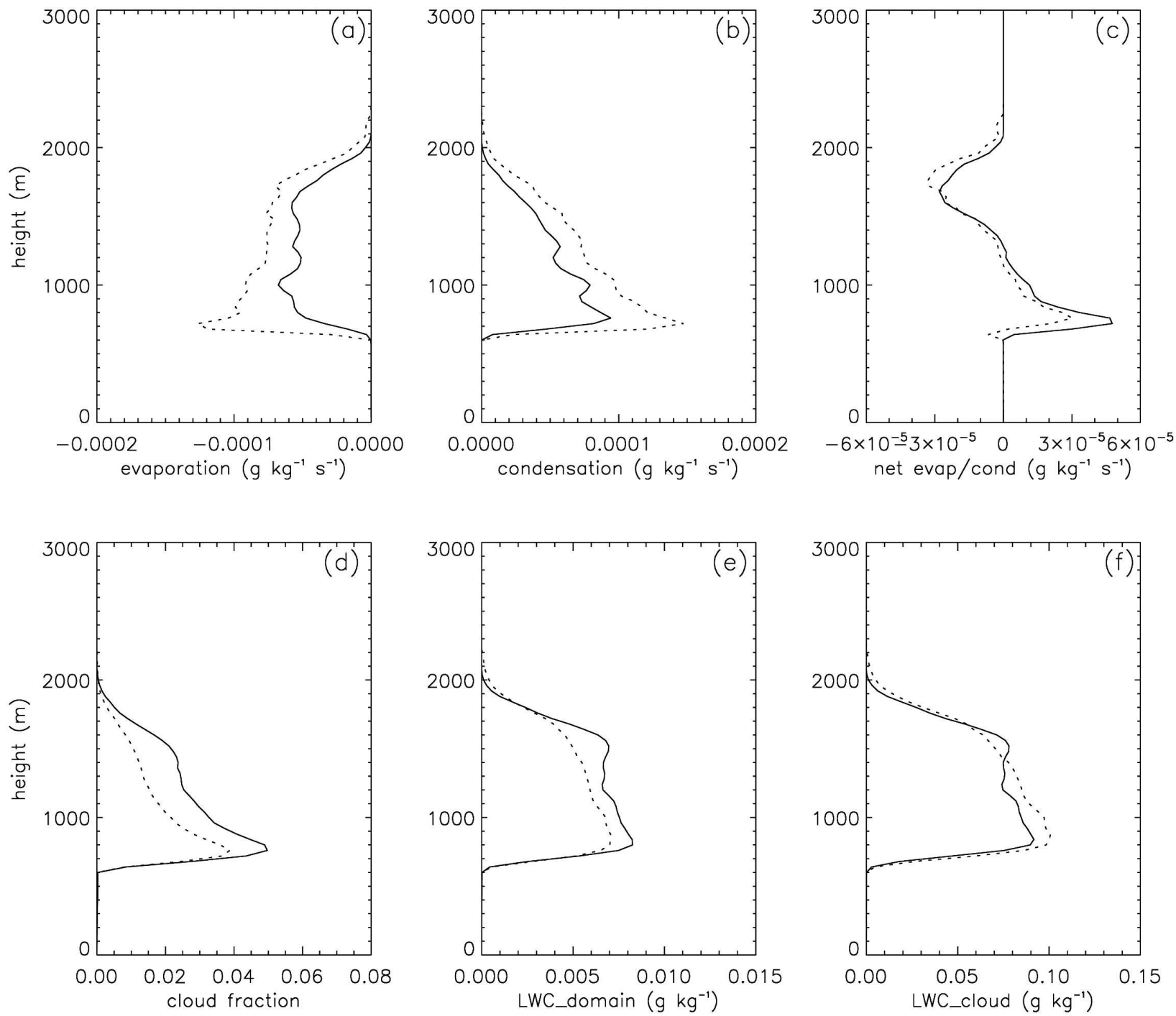

FIG. 6. Profiles averaged over the whole domain and the last $4 \mathrm{~h}$ of simulation [only (f) is averaged over the clouds] for the clean and polluted cases for the base runs: (a) water evaporation rate, (b) water condensation rate, (c) net evaporation/condensation rate, (d) cloud fraction, (e) domain-averaged LWC, and (f) cloud-averaged LWC.

and sedimentation was also performed. These simulations therefore include the effect of aerosol on dropsize-dependent condensation/evaporation rates but exclude precipitation feedbacks. An additional simulation that used a simple saturation adjustment scheme to simulate condensation/evaporation (no collisioncoalescence or precipitation) was also performed. The saturation adjustment scheme allows liquid water to condense whenever supersaturation exists. It does not specifically activate droplets, does not resolve a size distribution, and does not represent growth or precipitation processes. It assumes a very rapid phase-change relaxation time and serves as both an instantaneous evaporation limit and a no-precipitation limit. A sum- mary of various cloud properties for the higher surface flux case is given in Table 2. Results exhibit similar qualitative trends, namely, decreasing cloud fraction and cloud-top height with increasing aerosol. As expected, the saturation adjustment simulation is similar to the polluted simulation. There is a monotonic transition of cloud properties as the evaporation rate changes from slow (for clean conditions) to fast (for polluted conditions), and to very rapid evaporation. Therefore, the condensation/evaporation phase-change relaxation time does play an important role in determining the cloud response to aerosol and the effect is not primarily a sedimentation feedback. Note, however, that the overall effect of aerosol on these param- 
TABLE 2. Average cloud properties over the last $4 \mathrm{~h}$ of simulations for the higher surface flux case. Simulations include clean and polluted conditions (but no collision-coalescence or precipitation) as well as results from a simple saturation adjustment scheme.

\begin{tabular}{|c|c|c|c|}
\hline & \multicolumn{2}{|c|}{$\begin{array}{l}\text { No collision-coalescence } \\
\text { or precipitation }\end{array}$} & \multirow[b]{2}{*}{$\begin{array}{l}\text { Saturation } \\
\text { adjustment }\end{array}$} \\
\hline & $\begin{array}{c}N_{a}= \\
25 \mathrm{mg}^{-1}\end{array}$ & $\begin{array}{c}N_{a}= \\
2000 \mathrm{mg}^{-1}\end{array}$ & \\
\hline Cloud fraction & 0.119 & 0.101 & 0.097 \\
\hline LWP_domain $\left(\mathrm{g} \mathrm{m}^{-2}\right)$ & 14.3 & 12.6 & 12.6 \\
\hline LWP_cloud $\left(\mathrm{g} \mathrm{m}^{-2}\right)$ & 117 & 121 & 128 \\
\hline Cloud top (m) & 1306 & 1202 & 1185 \\
\hline Cloud base (m) & 856 & 854 & 852 \\
\hline $\operatorname{TKE}\left(\mathrm{kg} \mathrm{s}^{-2}\right)$ & 566 & 591 & 590 \\
\hline Cloud depth (m) & 450 & 348 & 333 \\
\hline
\end{tabular}

eters is reduced for parameters such as cloud fraction. Cloud fraction for the clean case is now 0.119 compared to 0.133 for the simulation with collision-coalescence and sedimentation (Tables 1 and 2). This can be explained by the fact that in the clean case, collisioncoalescence produces much larger drops and evaporation rates are much slower.

\section{b. Evaporation and entrainment}

The case has been made that differences in evaporation rates between clean and polluted simulations are an important control on cloud fields. To demonstrate the significant difference in the time scales of droplet evaporation in clean and polluted cases, single droplet evaporation rates are calculated using $r d r / d t \propto\left(r_{v}-r_{s}\right)$ (e.g., Pruppacher and Klett 1997), which is the theoretical basis for condensation/evaporation in the bin microphysics scheme. Calculations show that complete evaporation of a droplet with $r=20 \mu \mathrm{m}$ takes about 20 s while a droplet with $r=5 \mu \mathrm{m}$ evaporates in about 2 s at $\mathrm{RH}=90 \%, T=15^{\circ} \mathrm{C}$, and $p=850 \mathrm{mb}$, conditions representing the mixture of ambient and cloudy air in an entrainment event. Therefore, the time scales for droplet evaporation in clean and polluted cases differ by a factor of about 10 .

Similarly, when a population of droplets is considered, the phase relaxation time of condensation/evaporation can be shown to be inversely proportional to the product of droplet concentration $N$ and its average size $\bar{r}$ (Squires 1952). Assuming $N=15 \mathrm{~cm}^{-3}$ and $\bar{r}=20 \mu \mathrm{m}$ in the clean case, and $N=1500 \mathrm{~cm}^{-3}$ and $\bar{r}=5 \mu \mathrm{m}$ in the polluted case, the phase relaxation time differs by a factor of 15 ; that is, similar to that for a single droplet above.

Not only do droplet condensation/evaporation and precipitation directly regulate cloud liquid water, but they also lead to feedbacks to boundary layer structure and cloud properties. Previous studies have shown that evaporation at cloud top causes cooling and downward motion, thus increasing TKE and buoyancy gradients that can enhance mixing and entrainment (Blyth et al. 1988; Zhao and Austin 2005). Analysis of clouds generated by LES of this same BOMEX case by Zhao and Austin (2005; although at higher resolution than the current study: $\Delta x=\Delta y=\Delta z=25 \mathrm{~m}$ ) lends support to the theory of Blyth et al. (1988) that the entrainment process in growing clouds occurs at the ascending cloud top and mixed parcels then descend around the edge of the rising thermal into the wake region. A similar theory by Jonas (1990) also invokes a scenario in which environmental air from near cloud top sinks in a thin layer around the cloud and is then laterally entrained into the cloud. Cloud radar observations of trade cumulus (Kollias et al. 2001) are in general agreement with these conceptual models. Given the importance of the cloud-top interface with the environmental air, it is clear that the evaporation process in this region is of importance, as is the evaporation at the lateral interfaces.

Figure 7 shows domainwide downdraft- and updraftaveraged turbulence $\left(\overline{w^{\prime} w^{\prime}}\right)$ and buoyancy flux $\left(\overline{w^{\prime} \theta_{v}^{\prime}}\right)$ profiles. In the updrafts, $\overline{w^{\prime} w^{\prime}}$ and $\overline{w^{\prime} \theta_{v}^{\prime}}$ within the cloud layer tend to be larger for polluted than for clean conditions. Here $\overline{w^{\prime} \theta_{v}^{\prime}}$ is negative just near cloud top in the region above the limit of convection, where buoyancy is negative. In this region, $\overline{w^{\prime} \theta_{v}^{\prime}}$ is smaller (more negative) in the polluted case because of the larger $\overline{w^{\prime} w^{\prime}}$ and more significant overshooting of the limit of convection into regions of smaller (more negative) $\theta_{v}^{\prime}$. The downdraft-averaged profiles show clear evidence of evaporatively driven downdrafts near cloud top. These result in stronger $\overline{w^{\prime} w^{\prime}}$ and $\overline{w^{\prime} \theta_{v}^{\prime}}$ near cloud top in the case of the polluted clouds. The small region of in-cloud negative buoyancy at $\sim 1500 \mathrm{~m}$ is a result of downdrafts penetrating into regions of positively buoyant air. This region is more pronounced for the polluted clouds because of the stronger evaporation rates at cloud top. It is even more pronounced in the higher surface flux case described in section $3 \mathrm{~b}$ (figures not shown). Similar analysis was performed for cloudwide $\overline{w^{\prime} w^{\prime}}$ and $\overline{w^{\prime} \theta_{v}^{\prime}}$ profiles and yielded qualitatively similar results to Fig. 7 , with the differences between polluted and clean cases much more pronounced. (The domainwide average values are thus dominated by the cloudy regions.) In the interests of brevity, the figures are not shown.

Figure 8 shows profiles of buoyancy for positively and negatively buoyant regions for cloudy air, defined, ad hoc, based on an LWP threshold of more than 

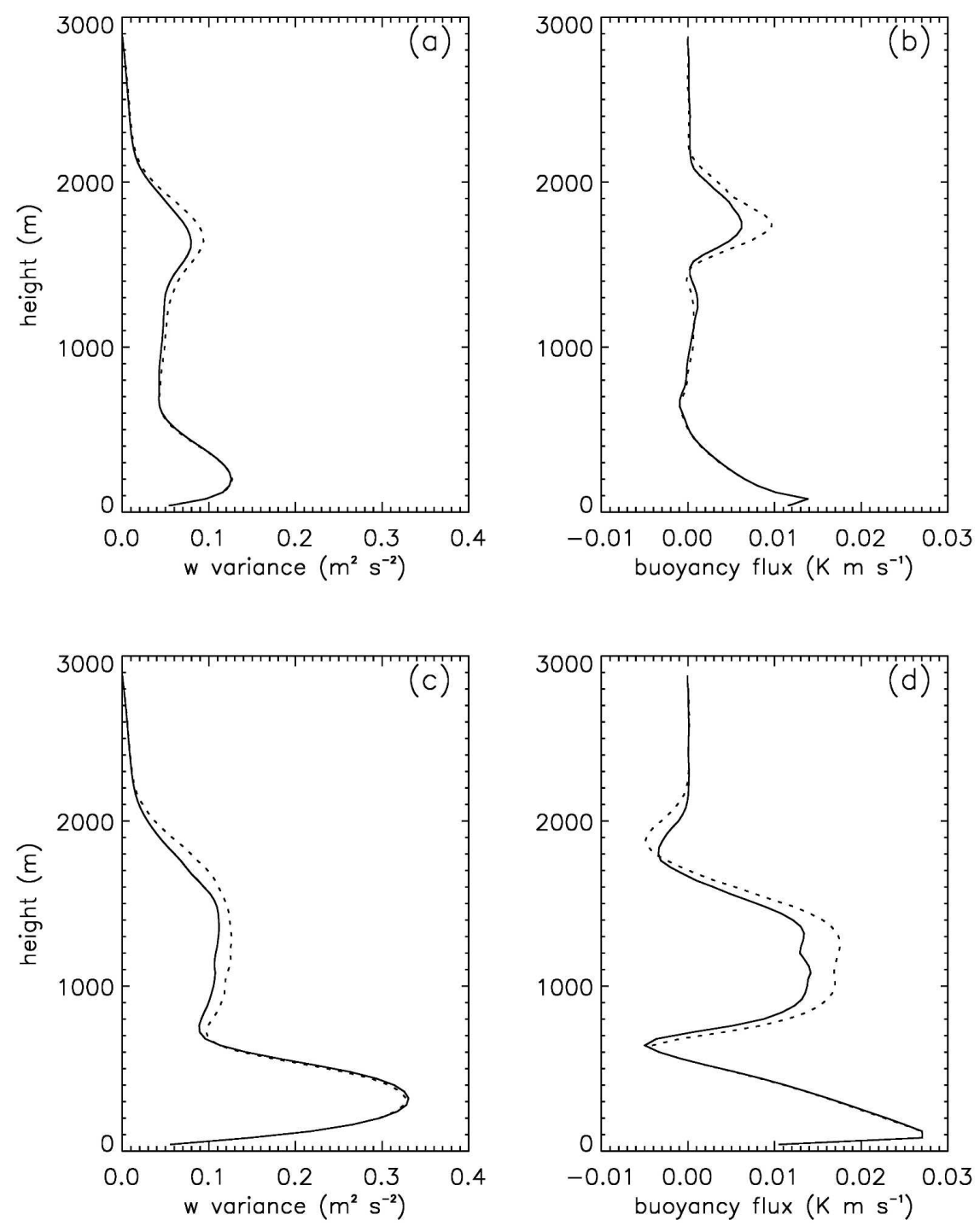

FIG. 7. Profiles of $w$ variance $\overline{w^{\prime} w^{\prime}}$ and buoyancy flux $\overline{w^{\prime} \theta_{v}^{\prime}}$ averaged over the last $4 \mathrm{~h}$ of simulation for the clean and polluted cases for the base runs: (a), (b) downdraft averages and (c), (d) updraft averages.

$1 \mathrm{~g} \mathrm{~m}^{-2}$. This allows the inclusion of cloud edges in this particular analysis. The polluted case has stronger negative buoyancy at cloud top. Zhao and Austin (2005) showed that the strength of entrainment is determined by the strength of the toroidal circulation around the core updraft, which is, in turn, proportional to the horizontal buoyancy gradient. As can be seen in Fig. 8, the polluted clouds have higher horizontal buoyancy gradients than their clean counterparts. This results in higher entrainment rates and explains the lower cloud fractions, lower cloud-top heights and cloud depths as discussed previously.

Figure 9 shows domainwide probability distribution functions (PDFs) of vertical velocity for clean and pol- luted clouds over the last $4 \mathrm{~h}$ of simulation. The PDFs are shown at a number of different levels below, within, and above clouds. Generally, the polluted clouds have both stronger updrafts and stronger downdrafts than the clean clouds, consistent with the TKE (Fig. 2) and cloud-buoyancy horizontal gradient differences (Fig. 8). Below cloud $(600 \mathrm{~m})$ the differences are negligible because of limited precipitation feedbacks. The same is true above cloud top (2200 $\mathrm{m}$ ) where cloud influence is minimal.

\section{c. Simulations at higher temporal-spatial resolution}

Because the entrainment-evaporation mechanism discussed here may be sensitive to small-scale mixing, 

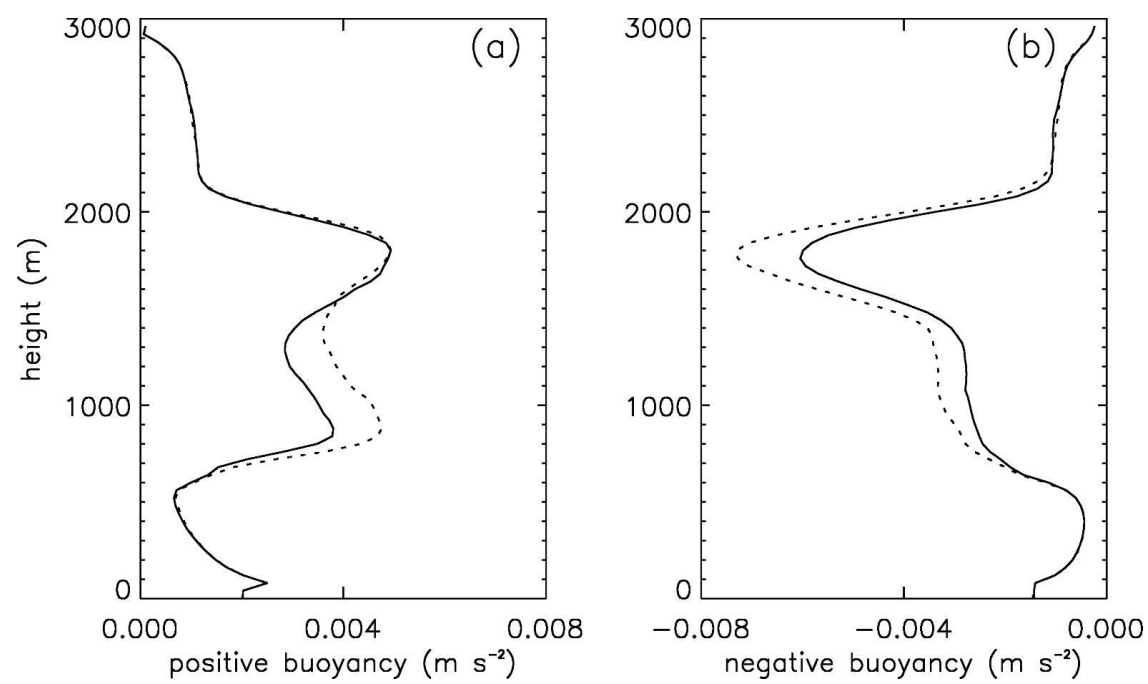

FIG. 8. Mean buoyancy profiles for cloudy regions defined as columns having LWP $>1 \mathrm{~g} \mathrm{~m}^{-2}$ (so as to include cloud edges) over the last $4 \mathrm{~h}$ of simulation for the clean and polluted cases for the base run: (a) positive buoyancy and (b) negative buoyancy. Horizontal buoyancy gradients are stronger in the polluted case.

sensitivity studies were performed at higher temporal and spatial resolution for the higher surface flux case for clean and polluted conditions. These simulations have $\Delta x=\Delta y=50 \mathrm{~m}(\Delta z=40 \mathrm{~m})$ and $\Delta t=0.5 \mathrm{~s}(\mathrm{a}$ factor of 3 smaller than previous simulations) and are run for a limited period of $t=2-4 \mathrm{~h}$ due to their large computational expense. A sample of results is summarized in Table 3. We see that the aerosol effects are still robust in these fine-resolution runs; the percentage decreases in cloud fraction, cloud-top height, and cloud depth are of similar order of magnitude to the original simulations. TKE also increases with increasing aerosol, although by a smaller amount. The only exception is cloud-averaged LWP, which decreases with increasing aerosol in the fine-resolution runs. This is at least partly due to the fact that the fields are averaged for only $2 \mathrm{~h}$. In addition, the precipitation amount is small for $t=2 \mathrm{~h}$ to $t=4 \mathrm{~h}$ (similar to Fig. 4) so that the removal of water by precipitation in the clean case is small and evaporation becomes the dominant process regulating cloud LWP.

Comparing the original runs to the higher-resolution runs (Tables 1 and 3), we see that cloud fraction and domain-averaged LWP are generally higher, but cloudaveraged LWP is lower in the higher-resolution runs. The increase in cloud fraction and domain-averaged LWP is consistent with the results of Stevens et al. (2001) who showed, with the same dynamical model, that cloud fraction increases as the grid is refined. The lower cloud-average LWP on the finer grid is consistent with results in Brown (1999). We refer the reader to these publications for further discussion.

\section{d. Distributions of cloud size and cloud depth}

Histograms of cloud size and cloud depth are shown in Fig. 10 for base and higher surface flux cases. The statistics shown here are based on 48 snapshots over the last $4 \mathrm{~h}$ of simulation (sampled once every $5 \mathrm{~min}$ ). Cloud size is defined as the square root of the area of the cloud (Neggers et al. 2003), where the area of the cloud is calculated from the area of the grid $(100 \mathrm{~m} \times$ $100 \mathrm{~m}$ ) multiplied by the number of grids occupied by each cloud. A grid is assumed to be cloudy if its LWP is at least $10 \mathrm{~g} \mathrm{~m}^{-2}$. Cloud depth is defined as the average value for each cloud. In both cases, the total number of clouds increases only slightly due to aerosol. However, the polluted clouds are smaller and have lower cloud depth, consistent with our prior discussion of stronger entrainment and more efficient evaporation of cloud droplets. Note too that the polluted case has a narrower distribution of cloud depths.

Regardless of whether one espouses the entrainment model of shedding thermals proposed by Blyth et al. (1988) and supported by the analysis of Kollias et al. (2001) or Zhao and Austin (2005), or the description of entrainment based on plume models, entrainment rates are inversely proportional to cloud radius. The smaller size of the polluted clouds increases the surface to volume ratio of the clouds and enhances their susceptibility to mixing between cloudy air and drier environmental air. This in turn reduces the size of the clouds even further. The fact that polluted clouds evaporate faster at all levels, and have smaller sizes and depths, suggests that both cloud-top and lateral entrainment are impor- 

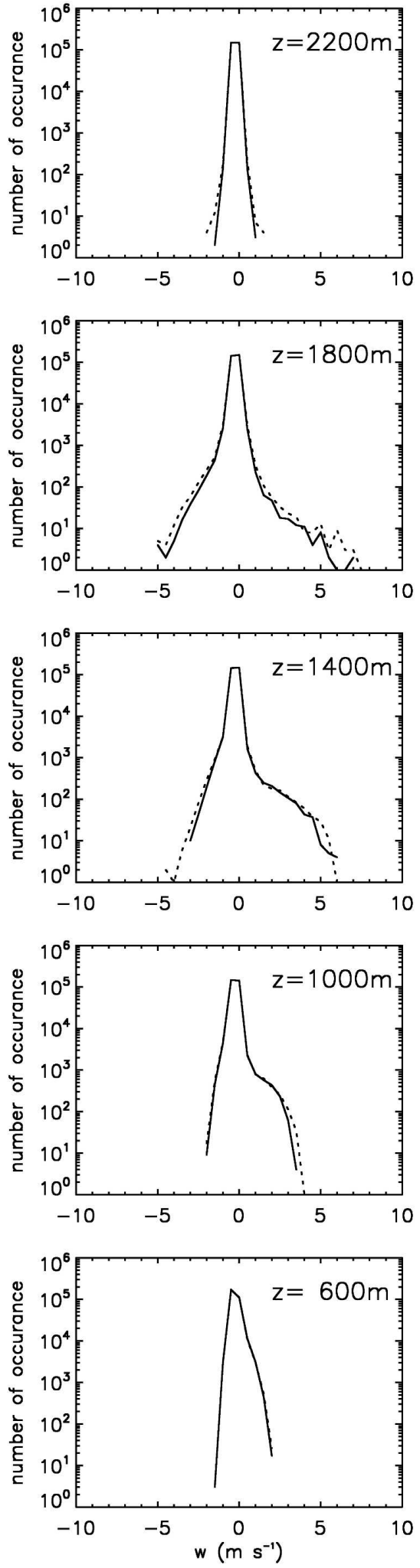

FIG. 9. PDFs of vertical velocity at various levels for the clean and polluted cases for the base runs.
TABLE 3. Average cloud properties over $t=2-4 \mathrm{~h}$ for the higher surface flux case and for higher temporal-spatial resolution $(\Delta x=$ $\Delta y=50 \mathrm{~m}, \Delta z=40 \mathrm{~m}, \Delta t=0.5 \mathrm{~s})$.

\begin{tabular}{|c|c|c|c|}
\hline & $\begin{array}{c}N_{a}= \\
25 \mathrm{mg}^{-1}\end{array}$ & $\begin{array}{c}N_{a}= \\
2000 \mathrm{mg}^{-1}\end{array}$ & $\begin{array}{l}\text { Diff } \\
(\%)\end{array}$ \\
\hline Cloud fraction & 0.172 & 0.132 & -23 \\
\hline LWP_domain $\left(\mathrm{g} \mathrm{m}^{-2}\right)$ & 19.3 & 14.1 & -27 \\
\hline LWP_cloud $\left(\mathrm{g} \mathrm{m}^{-2}\right)$ & 108 & 104 & - \\
\hline Cloud top (m) & 1341 & 1224 & -8 \\
\hline Cloud base (m) & 875 & 874 & -0 \\
\hline $\operatorname{TKE}\left(\mathrm{kg} \mathrm{s}^{-2}\right)$ & 520 & 528 & 1.5 \\
\hline Cloud depth (m) & 466 & 350 & -25 \\
\hline
\end{tabular}

tant for the shallow cumulus case studied and play a key role in determining cloud response to changes in aerosol.

A power-law function with an exponent of -1.7 is superimposed on Figs. 10a,c. It can be seen that there is a scale break in the power-law function at a cloud size of about $400 \mathrm{~m}$. Both the power-law exponent, and the size at which the scale break size occurs, are consistent with Neggers et al. (2003).

\section{e. Precipitation feedbacks}

Analysis of temperature and vapor soundings (not shown) exhibit no evidence of precipitation-induced stabilization that inhibits the mixing of the boundary layer, mainly because cloud fraction is relatively low in this case study and drizzling clouds are only a small fraction of the whole domain. As can be seen in the profiles of $\overline{w^{\prime} w^{\prime}}, \overline{w^{\prime} \theta_{v}^{\prime}}$ (Fig. 7), and cloud buoyancy (Fig. 8), the subcloud-layer fluxes exhibit negligible differences. Results for the more strongly precipitating set of simulations also show only minor influence of precipitation on stability.

\section{f. Relationship to other indirect effect studies}

Results presented here do not conform to some of the accepted ideas regarding the influence of aerosol on cloud properties, namely, that an increase in aerosol will result in increased LWP and cloud fraction. (The reduction in drop size, increase in optical depth, and decrease in precipitation associated with increases in aerosol are incontrovertible results.) It is important to consider that the second aerosol indirect hypothesis emanates from Albrecht's (1989) study of stratocumulus, which employed a 1D turbulence closure model with relatively simple microphysical representation, and it should perhaps not be surprising that cloud response to aerosol might vary both because of differences in cloud type (cumulus versus stratocumulus) and 

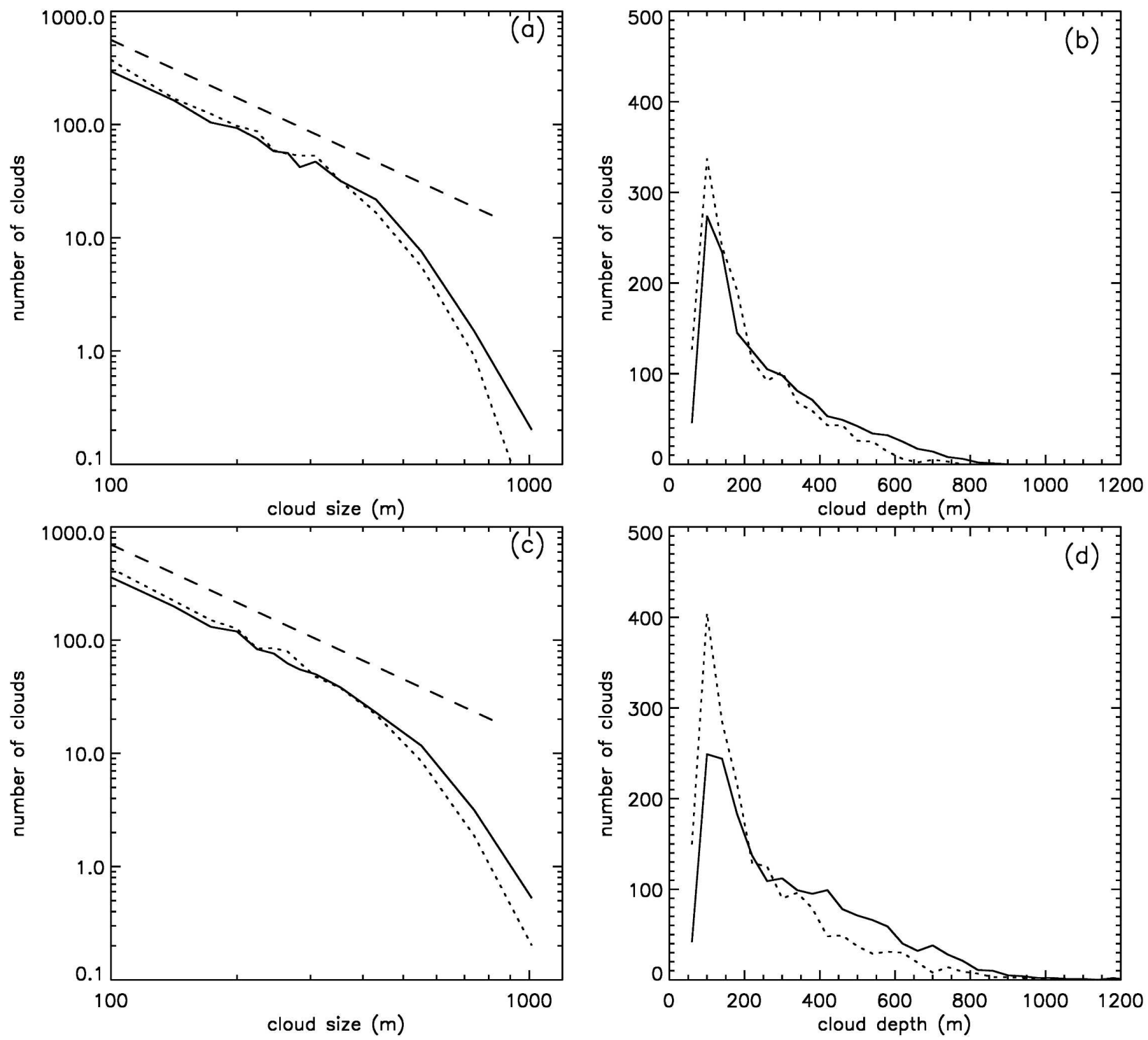

FIG. 10. Histograms of cloud area and cloud depth for (a), (b) base simulations and (c), (d) higher flux simulations. The long dashed line with exponent -1.7 is plotted for comparison to Neggers et al. (2003). Counts less than 1 result from averaging to improve counting statistics at the larger cloud sizes.

type of model. Only recently have remote sensing observations provided some indication of the response of cloud fraction and path integrated properties such as optical depth to changes in aerosol. Over the Atlantic, Kaufman et al. (2005) have recently shown increases in cloud fraction and cloud optical depth with increasing aerosol amount (as represented by column-integrated aerosol optical depth in cloud free-columns adjacent to clouds). It is noteworthy that their results pertain to clouds with areal coverage greater than about $10 \mathrm{~km}^{2}$ and cloud fractions on the order of $20 \%-60 \%$-values significantly larger than those in the trade cumulus clouds studied here (e.g., Figs. 2 and 10). The small clouds under examination here have cloud fractions of $10 \%-15 \%$ and areal coverage of less than $1 \mathrm{~km}^{2}$ and are only poorly studied, although they may constitute $40 \%$ of the cloud fraction associated with small cumulus clouds (McFarquhar et al. 2004). Norris (2001) found that cloud fraction has increased slightly over the past $40 \mathrm{yr}$ in the Indian Ocean, during which time the aerosol loadings have increased significantly. Interpretation of those results is difficult because they likely include effects that are both microphysical (i.e., the second indirect effect) as well as radiative (i.e., the aerosol semidirect effect which results in reductions in cloud fraction; e.g., Feingold et al. 2005). For example, obser- 
vations from the Indian Ocean Experiment (INDOEX) have shown that cloud coverage and depth decrease with increasing aerosol for trade cumuli while cloud LWC is approximately the same for clean and polluted conditions (Heymsfield and McFarquhar 2001; McFarquhar et al. 2004). Changes in cloud coverage and depth with increasing aerosol in that case were attributed to the dominance of the aerosol absorptive heating over aerosol indirect effects, although it is difficult to separate these mechanisms in the observations. The present study suggests another mechanism, namely, feedbacks due to drop-size-dependent evaporation rates that might be independently (i.e., regardless of absorption warming) responsible for the changes of cloud size, depth, and coverage in trade cumuli.

Results in this study are generally consistent with Jiang and Feingold (2006), who simulated the effects of aerosol on cloud properties for warm continental cumulus with a different large-eddy simulation model coupled to a surface soil and vegetation model. Aerosol effects on clouds were similar to those described here, with the exception that when surface model responses to aerosol were neglected cloud-averaged LWP and cloud fraction changed little with increasing aerosol. Coupling of the surface model resulted in a decrease in LWP with increasing aerosol as a result of reduced incoming solar radiation at the surface, and reduced surface fluxes. Generalizing the response of small cumulus clouds to aerosol seems premature given the likely dependence on atmospheric sounding (e.g., Ackerman et al. 2004) and cloud size. Nevertheless, we speculate, based on the results of Kaufman et al. (2005) that small and large clouds may have opposite responses to increasing aerosol. Increases in aerosol may increase the size of large clouds since they have a smaller surface area to volume ratio and are therefore less susceptible to entrainment drying; in this case the effects of reduction in cloud water due to precipitation may dominate the counteracting effects of increased evaporation.

\section{Conclusions}

The LES of small trade cumuli presented here have shown that increases in aerosol lead to suppressed precipitation, increased cloud optical depth, cloudaveraged LWP and TKE, but lower cloud fraction, cloud size, cloud-top height and depth. The individual polluted clouds also have smaller areal coverage than their clean counterparts.

Cloud properties are modified by multiple physical mechanisms that might counter one another. For ex- ample, an increase in aerosol concentration results in more efficient droplet evaporation and entrainment along with the suppression of drizzle; these processes act in opposite directions in regulating the cloud water content. The resulting cloud properties are likely to be different under different conditions, depending on which mechanism dominates. In the small cumulus clouds studied here, the faster evaporation rate of smaller droplets associated with polluted conditions generates dynamical feedbacks that lead to smaller and shallower clouds. The stronger evaporative cooling and downward motion in the polluted case enhances TKE and horizontal buoyancy gradients, which in turn leads to more entrainment and evaporation, constituting a positive feedback. The effect of drizzle on the stability of the boundary layer through redistribution of heat and moisture is found to be small because of the relatively small precipitation rates and the fact that the precipitating clouds cover only a small fraction of the domain. For the simulations with higher surface fluxes, higher LWP, and therefore the potential for higher precipitation, evaporation still shows a strong influence of cloud properties. These influences are again manifested in smaller cloud fractions, cloud sizes, and cloud depths. Our results suggest that droplet evaporation and the resulting microphysical-dynamical feedbacks in trade cumulus clouds are important and need to be considered when studying the aerosol indirect effects.

In addition to aerosol effects on cloud size, cloud depth, and number of clouds it is possible that cloud lifetimes are different for clean and polluted conditions, which warrants further studies using cloud tracking tools such as those developed by Zhao and Austin (2005). This is currently being explored.

Finally, we point out that although the changes in cloud properties due to aerosol are robust in the mean fields, the standard deviations of cloud properties such as LWP at any given aerosol concentration are usually larger than the changes caused by aerosol, even for rather extreme changes $\left(N_{a}=25 \mathrm{mg}^{-1}\right.$ versus 2000 $\left.\mathrm{mg}^{-1}\right)$. The cloud optical depth response to aerosol is much more robust. Nevertheless, the dynamical variability in evolving cloud systems such as these might impose difficulties in identifying the second aerosol indirect effect in trade cumulus clouds. This, together with the fact that it is difficult to assess radiative forcing in broken cloud fields, suggests that evaluation of the aerosol indirect effect for small cumulus clouds will be challenging.

Acknowledgments. We are grateful to Bjorn Stevens for providing the LES model and helpful suggestions on this paper. Helpful discussions with Hongli Jiang are 
also appreciated. Huiwen Xue acknowledges the National Research Council for a postdoctoral fellowship. Both authors acknowledge support from NOAA's Climate Goal and NSF Grant 0342647 for Rain in Cumulus over the Ocean (RICO).

\section{REFERENCES}

Ackerman, A. S., M. P. Kirkpatrick, D. E. Stevens, and O. B. Toon, 2004: The impact of humidity above stratiform clouds on indirect aerosol climate forcing. Nature, 432, 1014-1017.

Albrecht, B., 1989: Aerosols, cloud microphysics, and fractional cloudiness. Science, 245, 1227-1230.

Blyth, A. M., W. A. Cooper, and J. B. Jensen, 1988: A study of the source of entrained air in Montana cumuli. J. Atmos. Sci., 45, 3944-3964.

Brenguier, J.-L., H. Pawlowska, L. Schuller, R. Preusker, and J. Fischer, 2000: Radiative properties of boundary layer clouds: Droplet effective radius versus number concentration. $J$. Atmos. Sci., 57, 803-821.

Brown, A. R., 1999: The sensitivity of large-eddy simulations of shallow cumulus convection to resolution and subgrid model. Quart. J. Roy. Meteor. Soc., 125, 469-482.

Clark, T. L., 1974: A study in cloud phase parameterization using the gamma function. J. Atmos. Sci., 31, 142-155.

Coakley, J. A., and C. D. Walsh, 2002: Limits to the aerosol indirect radiative effect derived from observations of ship tracks. J. Atmos. Sci., 59, 668-680.

Durkee, P. A., K. J. Noone, and R. T. Bluth, 2000: The Monterey area ship track experiment. J. Atmos. Sci., 57, 2523-2541.

Feingold, G., 2003: Modeling of the first indirect effect: Analysis of measurement requirements. Geophys. Res. Lett., 30, 1997, doi:10.1029/2003GL017967.

_ B. B. Stevens, W. R. Cotton, and A. S. Frisch, 1996: The relationship between drop in-cloud residence time and drizzle production in numerically simulated stratocumulus clouds. $J$. Atmos. Sci., 53, 1108-1122.

— - W. R. Cotton, S. M. Kreidenweis, and J. T. Davis, 1999: Impact of giant cloud condensation nuclei on drizzle formation in marine stratocumulus: Implications for cloud radiative properties. J. Atmos. Sci., 56, 4100-4117.

— W. L. Eberhard, D. E. Veron, and M. Previdi, 2003: First measurements of the Twomey indirect effect using groundbased remote sensors. Geophys. Res. Lett., 30, 1287, doi:10.1029/2002GL016633.

- H. Jiang, and J. Harrington, 2005: On smoke suppression of clouds and Amazonia. Geophys. Res. Lett., 32, L02804, doi:10.1029/2004GL021369.

Ferek, R. J., and Coauthors, 2000: Drizzle suppression in ship tracks. J. Atmos. Sci., 57, 2707-2728.

Han, Q., W. B. Rossow, J. Zeng, and R. Welch, 2002: Three different behaviors of liquid water path of water clouds in aerosol-cloud interactions. J. Atmos. Sci., 59, 726-735.

Heymsfield, A. J., and G. M. McFarquhar, 2001: Microphysics of INDOEX clean and polluted trade cumulus clouds. J. Geophys. Res., 106, 28 653-28 673.

Holland, J. Z., 1972: Comparative evaluation of some BOMEX measurements of sea surface evaporation, energy flux, and stress. J. Phys. Oceanogr., 2, 476-486.

— , and E. M. Rasmusson, 1973: Measurements of the atmo- spheric mass, energy, and momentum budgets over a 500 kilometer square of tropical ocean. Mon. Wea. Rev., 101, 44 57.

Hudson, J. G., and S. S. Yum, 2001: Maritime-continental drizzle contrasts in small cumuli. J. Atmos. Sci., 58, 915-926.

Jiang, H., and W. R. Cotton, 2000: Large-eddy simulation of shallow cumulus convection during BOMEX: Sensitivity to microphysics and radiation. J. Atmos. Sci., 57, 582-594.

- and G. Feingold, 2006: The effect of aerosol on warm convective clouds: Aerosol-cloud-surface flux feedbacks in a new coupled large eddy model. J. Geophys. Res., 111, D01202, doi:10.1029/2005JD006138.

— - _ and W. R. Cotton, 2002: Simulations of aerosolcloud-dynamical feedbacks resulting from entrainment of aerosol into the marine boundary layer during the Atlantic Stratocumulus Transition Experiment. J. Geophys. Res., 107, 4813, doi:10.1029/2001JD001502.

Jonas, P. R., 1990: Observations of cumulus cloud entrainment. Atmos. Res., 25, 105-127.

Kaufman, Y. J., and T. Nakajima, 1993: Effect of Amazon smoke on cloud microphysics and albedo-analysis from satellite imagery. J. Appl. Meteor., 32, 729-744.

- I. Koren, L. A. Remer, D. Rosenfeld, and Y. Rudich, 2005: The effect of smoke, dust, and pollution aerosol on shallow cloud development over the Atlantic Ocean. Proc. Natl. Acad. Sci., 102, 11 207-11 212.

Kollias, P., B. A. Albrecht, R. Lhermitte, and A. Savtchenko, 2001: Radar observations of updrafts, downdrafts, and turbulence in fair weather cumuli. J. Atmos. Sci., 58, 1750-1766.

Leaitch, W. R., C. M. Banic, G. A. Issac, M. D. Couture, P. S. K. Liu, I. Gultepe, and S.-M. Li, 1996: Physical and chemical observations in marine stratus during the 1993 North Atlantic Regional Experiment: Factors controlling cloud droplet number concentrations. J. Geophys. Res., 101, 29 132-29 135.

Lohmann, U., and J. Feichter, 2004: Global indirect aerosol effects: A review. Atmos. Chem. Phys. Discuss., 4, 7561-7614.

Lu, M.-L., and J. H. Seinfeld, 2005: Study of the aerosol indirect effect by large-eddy simulation of marine stratocumulus. $J$. Atmos. Sci., 62, 3909-3932.

McFarquhar, G. M., S. Platnick, L. Di Girolamo, H. Wang, G. Wind, and G. Zhao, 2004: Trade wind cumuli statistics in clean and polluted air over the Indian Ocean from in situ and remote sensing measurements. Geophys. Res. Lett., 31, L21105, doi:10.1029/2004GL020412.

Neggers, R. A. J., H. J. J. Jonker, and A. P. Siebesma, 2003: Size statistics of cumulus cloud populations in large-eddy simulations. J. Atmos. Sci., 60, 1060-1074.

Norris, J. R., 2001: Has northern Indian Ocean cloud cover changed due to increasing anthropogenic aerosol? Geophys. Res. Lett., 28, 3271-3274.

Platnick, S., and Coauthors, 2000: The role of background cloud microphysics in the radiative formation of ship tracks. J. Atmos. Sci., 57, 2607-2624.

Pruppacher, H. R., and J. D. Klett, 1997: Microphysics of Clouds and Precipitation. $2 \mathrm{~d}$ ed. Kluwer Academic, 954 pp.

Siebesma, A. P., and Coauthors, 2003: A large-eddy simulation intercomparison study of shallow cumulus convection. J. Atmos. Sci., 60, 1202-1219.

Squires, P., 1952: The growth of cloud droplets by condensation. Aust. J. Sci. Res., 5, 66-86.

Stevens, B., G. Feingold, W. R. Cotton, and R. L. Walko, 1996: Elements of the microphysical structure of numerically simu- 
lated nonprecipitating stratocumulus. J. Atmos. Sci., 53, 9801006.

— W. W. Cotton, G. Feingold, and C.-H. Moeng, 1998: Largeeddy simulations of strongly precipitating, shallow, stratocumulus-topped boundary layers. J. Atmos. Sci., 55, 3616-3638.

_ C.-H. Moeng, and P. P. Sullivan, 1999: Large-eddy simulations of radiatively driven convection: Sensitivities to the representation of small scales. J. Atmos. Sci., 56, 3963-3984.

_ der a strong inversion. J. Atmos. Sci., 58, 1870-1890.

Twomey, S., 1974: Pollution and the planetary albedo. Atmos. Environ., 8, 1251-1256.

_ 1977: The influence of pollution on the shortwave albedo of clouds. J. Atmos. Sci., 34, 1149-1152.

—, 1991: Aerosols, clouds and radiation. Atmos. Environ., 25, 2435-2442.

Tzivion, S., G. Feingold, and Z. Levin, 1987: An efficient numeri- cal solution to the stochastic collection equation. J. Atmos. Sci., 44, 3139-3149.

Warner, J., 1968: A reduction in rainfall associated with smoke from sugar-cane fires-An inadvertent weather modification? J. Appl. Meteor., 7, 247-251.

- , and S. Twomey, 1967: The production of cloud nuclei by cane fires and the effect on cloud droplet concentration. $J$. Atmos. Sci., 24, 704-706.

Warren, S. G., C. J. Hahn, J. London, R. M. Chervine, and R. L. Jenne, 1986a: Global distribution of total cloud cover and cloud type amounts over land. NCAR Tech. Note NCAR/ TN-273+STR, 29 pp.

,,,$--- \ldots$, and $-1986 \mathrm{~b}$ : Global distribution of total cloud cover and cloud type amounts over ocean. NCAR Tech. Note NCAR/TN-317+STR, 42 pp.

Zhao, M., and P. H. Austin, 2005: Life cycle of numerically simulated shallow cumulus clouds. Part I: Transport. J. Atmos. Sci., 62, 1269-1290. 